\title{
Estimation of Peak Ground Acceleration (PGA) and Spectral Acceleration (Sa) Vertical Component for Interface Subduction Zone Earthquakes of North- east India (NEI) and Adjacent Regions
}

Rahman Tauhidur ( $\sim$ tauhid_srm@yahoo.com )

NIT Silchar

Ricky L Chhangte

National Institute of Technology Silchar

Research Article

Keywords: Spectral Acceleration, Vertical Component, Zone Earthquakes

Posted Date: October 18th, 2021

DOI: https://doi.org/10.21203/rs.3.rs-873536/v1

License: (c) (1) This work is licensed under a Creative Commons Attribution 4.0 International License.

Read Full License 


\title{
Estimation of Peak Ground Acceleration (PGA) and Spectral Acceleration $\left(S_{a}\right)$ Vertical Component for Interface Subduction Zone Earthquakes of North-east India (NEI) and Adjacent Regions
}

\author{
Dr. Tauhidur Rahman ${ }^{1}$, Ricky L. Chhangte ${ }^{2}$
}

\section{Summary}

This article presented ground motion model (GMM) for vertical peak ground acceleration (PGA) and pseudo spectral acceleration $\left(\mathrm{S}_{\mathrm{a}}\right)$ at $5 \%$ damping for North-east India (NEI) and adjacent regions at a time period of 0.01 to $5 \mathrm{~s}$, and hypocentral distance 40 to $300 \mathrm{~km}$. We used combined point source $\left(4.5 \leq \mathrm{M}_{\mathrm{w}} \leq 6.5\right)$ and finite fault model $\left(6.5<\mathrm{M}_{\mathrm{w}} \leq 9.5\right)$ (refer as combined model) to develop GMM for vertical component of ground motion (VCGM) for the region. The vertical GMM obtained is validated with the available recorded events in NEI and adjacent regions for the interface subduction zone earthquakes. It is observed that peak ground accelerations and spectral accelerations are 55 to $65 \%$ lesser than the horizontal components of ground motions. VCGM parameters obtained in this study play an important role in designing low rise buildings and linear superstructures such as bridges, silos and chimneys.

\section{Introduction}

This article is a companion article published by Rahman and Chhangte (2021). Rahman and Chhangte (2021) developed ground motion model (GMM) for the horizontal component of peak ground acceleration (PGA) and 5\% damping spectral acceleration $\left(\mathrm{S}_{\mathrm{a}}\right)$ for the interface subduction earthquakes of NEI and adjacent regions (hereon refer as NEI). Seismo-tectonic characteristics of the interface subduction zone earthquakes of NEI was presented in details in the companion article (Rahman and Chhangte, 2021).

Beside the horizontal component of ground motions, vertical component of ground motions (VCGM) parameter also induced damage in the buildings, bridges and other engineering structures for the high magnitude earthquakes. Based on the past seismicity, many researchers have predicted that NEI may face high magnitude $\left(\mathrm{M}_{\mathrm{w}}>8.0\right)$ interface zone earthquakes in future (Rahman and Chhangte, 2021; Singh et al., 2016; Steckler et al., 2016; Rahman, 2012; Goswami and Sharma, 1982). The vertical ground motions obtained from this high magnitude

${ }^{1}$ Associate Professor, NIT Silchar, Assam, India, 788010

${ }^{2}$ Research Scholar, NIT Silchar, Assam, India, 788010 
earthquakes $\left(\mathrm{M}_{\mathrm{w}}>8.0\right)$ cannot be ignored in designing the engineering structures. The vertical ground motion obtained from the subduction earthquakes $\left(\mathrm{M}_{\mathrm{w}} 8.5\right)$ which occurred in 1897 in NEI was estimated to be $1.1 \mathrm{~g}$ (Oldham, 1899). Rahman (2008) had simulated VCGM for earthquake $\mathrm{M}_{\mathrm{w}} 8.0$ using Empirical Green Function (EMF) approach based on earthquake of $\mathrm{M}_{\mathrm{w}}$ 5.9 occurred in $18^{\text {th }}$ May 1987 at the recording station namely Bamungaon, Berlongfar and Laisong. He observed that simulated VCGM at these 3 recording stations for earthquake of $\mathrm{M}_{\mathrm{w}}$ 8.0 were $0.82 \mathrm{~g}, 0.65 \mathrm{~g}$ and $0.81 \mathrm{~g}$ respectively. This type of vertical component induced due to high magnitude interface earthquakes is disastrous for man-made structures. This higher value of vertical strong motions may uplift or throw low-rise building, bridges and other engineering structures. The strong ground motion parameter due to vertical component may also overturn a high rise building during liquefaction. An interface subduction earthquake of $\mathrm{M}_{\mathrm{w}} 8.7$ occurred on 1950 in the region which has uplifted several bridges. This earthquake had also uplifted and buckled the railway line track laid from Guwahati city to Dibrugarh town for several $100 \mathrm{~km}$. This earthquake had also diverted the line of course of the river Brahamaputra from the original mainstream. The vertical ground motions for this earthquake were estimated as $1.2 \mathrm{~g}$ (Raghukanth, 2008; Rahman, 2008; Tiwari, 2002).

Based on this study, it is observe that vertical component of earthquakes also contribute to the destructive effect on structures as well. In the past, VCGM were totally ignored while designing ordinary structures as it was commonly believed that vertical ground accelerations are significantly lower than corresponding horizontal ground accelerations (Cagnan et al. 2017).

In this article, we have simulated 50,000 vertical component of PGA and $\mathrm{S}_{\mathrm{a}}$ for $4.5 \leq \mathrm{M}_{\mathrm{w}} \leq 6.5$ using Boore's $(1983 ; 2003)$ point source seismological model. We have also simulated 50000 vertical component of ground motion for $6.5<\mathrm{M}_{\mathrm{w}} \leq 9.5$ using finite fault model. We used combined point source and finite fault model as point source have some limitation in ground motion simulation for high magnitude earthquake (Rahman and Chhangte, 2021).

54 We used the same data and resources, path duration, geometrical spreading factor, stress drops 55 for the interface subduction earthquakes presented in our companion article (Rahman and 56 Chhangte, 2021). 
57 We have estimated quality factor $(Q)$ for VCGM which are further used in ground motion 58 simulations for vertical component using the combined point source and finite fault model 59 (called combined model). The 12 NEI seismic events considered in this article for the analysis of 60 vertical component of ground motions for Boore $(1983 ; 2003)$ point source and FINSIM finite 61 fault model is presented in Table 1. The seismo-tectonic map and the earthquakes considered in 62 this article are shown in Figure 1.

\section{Estimation of Quality Factor $\left(Q_{V}\right)$ for VCGM}

64 We used the same mathematical technique of Rahman and Chhangte (2021) to estimate the 65 quality factor $\left(Q_{V}\right)$ for the vertical component of 12 number of strong motion records for the 66 interface subduction earthquakes (Table 2).

$67 \log _{10} A+(1 / 5) \log _{10} R$ versus $R$ is plotted in Figures 2 (a) to (f) for VCGM of $Q_{V}(f)$ at the 68 frequency of $0.2 \mathrm{~Hz}$ for $10^{\text {th }}$ September $1986,18^{\text {th }}$ May $1987,6^{\text {th }}$ February $1988,8^{\text {th }}$ May 1997 , $699^{\text {th }}$ December 2004 and $3^{\text {rd }}$ January 2017 earthquakes respectively.

70 The dependence of $Q_{V}(f)$ on $f$ is given in Figures 3 (a) to (f) for VCGM of $10^{\text {th }}$ September 1986, $7118^{\text {th }}$ May 1987, $6^{\text {th }}$ February 1988, $8^{\text {th }}$ May 1997, 9 $9^{\text {th }}$ December 2004 and $3^{\text {rd }}$ January 2017 72 earthquakes respectively.

73 In this article, $Q_{V}(f)$ value for the 12 strong motion events for the VCGM of NEI interface 74 earthquakes are presented in Table 2. The average of the vertical component of $Q$ for all 12 75 interface earthquakes for NEI is calculated as

$76 Q_{V T}(f)=106.84 f^{0.95}$

77 with the standard deviation $\left(\sigma_{1}\right)$ values as $\left(13.7\left(Q_{0}\right), 0.038(\eta)\right)$.

78 The boot-strap method is applied similar to our companion paper Rahman and Chhangte (2021). 79 The operation is repeated 150 times and 150 sets of parameters are generated from which we can 80 draw distributions that represents the observed variability of the $Q_{V}$ shown in Figures 4 (a) and 81 (b). The anelastic model parameters obtained for $Q_{V}(f)$ using bootstrap technique $\operatorname{are} \log _{10}\left(Q_{0}\right)$ as $82 \quad 2.34 \pm 0.16, \gamma=1.02 \pm 0.007$ and $\eta=0.91-0.99$ presented in Table 3 . 
The ranges of seismic input parameters used for VCGM simulations of NEI interface earthquakes are presented in Table 3. Ground motions are simulated similar to Rahman and Chhangte (2021). Smaller range of $\mathrm{M}_{\mathrm{w}}$ (4.5 to 6.5) and hypocentral distance (30 to $300 \mathrm{~km}$ ) corresponding to $\mathrm{V}_{\mathrm{S} 30}$ as $2800 \mathrm{~m} / \mathrm{s}$ are simulated using point source model. There are 500 scenario pairs of magnitude and distance bins from which 50,000 ground motions are simulated for smaller magnitude to develop the GMM for NEI interface earthquakes vertical component of ground motion. For each scenario, 100 sets of ground motions are simulated which presented in

92 Table 4.

Region specific seismic input parameters for NEI used in the program SMSIM for point source model and FINSIM for finite fault model are presented in Table 5. For NEI finite fault modelling for vertical components of ground motions, we used Strasser et al. (2010) equation to estimate the size of subfault valid for interface subduction earthquakes;

$97 \quad M w=a_{1}+b_{1} x \log _{10}(L)$

$98 \quad M w=a_{2}+b_{2} x \log _{10}(W)$

$99 \quad M w=a_{3}+b_{3} x \log _{10}(A)$

100 where $L, W$ and $A$ are the length, width and area of the fault. The constants $a_{1}$ to $a_{3}$ and $b_{1}$ to $b_{3}$ 101 are regression coefficients in Equations (2) to (4) which were calculated by Strasser et al. (2010) 102 for NEI interface earthquakes which are presented in Table 6.

\section{GMM for VCGM for Interface Subduction Zone at Hard Rock Level}

104 The following functional GMM form used by Abrahamson et al. (2016) for global interface 105 subduction earthquakes is used in this study. The same mathematical form is also used in 106 Rahman and Chhangte (2021). The functional GMM form is as follow:

$107 \ln \left(S_{a}\right)=\theta_{1}+\theta_{4} \Delta C_{1}+\left(\theta_{2}+\theta_{3}\left(M_{w}-7.8\right)\right) \ln \left(R+C_{2} \exp \left(\theta_{7}\left(M_{w}-6\right)\right)\right)+\theta_{6} R+f_{m a g}\left(M_{w}\right)+\theta_{10}+$

$108 f_{\text {site }}\left(P G A_{1000}, V_{S 30}\right)$

109 where

$110 \theta_{1}-\theta_{10}=$ regression coefficients

111 For NEI, $F_{F A B A}=0$ considering NEI being an unknown site. 
$112 f_{\text {mag }}\left(M_{w}\right)=\left\{\frac{\theta_{4}\left(M_{w}-\left(C_{1}+\Delta C_{1}\right)+\theta_{9}\left(10-M_{w}\right)^{2}\right.}{\theta_{5}\left(M_{w}-\left(C_{1}+\Delta C_{1}\right)+\theta_{9}\left(10-M_{w}\right)^{2}\right.} \frac{\text { for } M_{w} \leq C_{1}+\Delta C_{1}}{\text { for } M_{w}>C_{1}+\Delta C_{1}}\right.$

113 where $C_{1}=7.8$. The values of $\Delta C_{1}$ is period-dependent variations based on the size of the NEI 114 interface earthquake.

$115 f_{\text {site }}\left(P A_{1000}, V_{S 30}\right)=\left\{\theta_{8} \operatorname{Ln}\left(\frac{V_{S}}{V_{\text {lin }}}\right)-b \operatorname{Ln}\left(P G A_{1000}+c\right)+b \operatorname{Ln}\left(P G A_{1000}+c\left(\frac{V_{S}}{V_{\text {lin }}}\right)^{n}\right)\right\}$

or

120 Here, $V_{S 30}=2800 \mathrm{~m} / \mathrm{s}$

121 The regression coefficients in Equation (5) are presented in Tables 7 and 8.

122 The regression coefficients $\theta_{1}$ to $\theta_{11}$ are calculated using a Joyner and Boore (1981) two-stage 123 regression method (Joyner and Boore, 1981) to check and minimize the errors in calculation of 124 regression coefficients. Sensivity analysis is also carried out to check the errors for the various 125 seismic input parameters used in this study.

126 Site coefficient $\left(\mathrm{F}_{\mathrm{S}}\right)$ for all sites class can be expressed using Iyenger and Raghukanth (2004) and 127 Singh et al. (2016). The site coefficients equation is as follows;

$128 \ln \left(F_{s}\right)=a_{1} Y_{b r}+a_{2}+\ln \left(\sigma_{s}\right)$

129 where $Y_{b r}$ is the hard rock acceleration and $\sigma_{s}$ are the standard deviations which were assigned for 130 NEI for Site Classes A to D (Singh et al., 2016).

\section{Sensitivity Analysis}

132 The sensitivity analysis performed in this study for different parameters is similar to the 133 procedure adopted by Rahman and Chhangte (2021). The sensitivity analysis results obtained 134 from our model are presented in Table 9.

135 It is observed that the spread of standard deviations for VCGM input parameters vary from 0.042 136 to 0.416 (Table 9). The standard deviations input parameters namely focal depth, cut-off 137 frequency, stress drop, radiation pattern, anelastic attenuation, geometric attenuation and time 
duration are negligible (Table 9). The small distribution of standard deviation give the impression that the developed GMM for VCGM is not biased with respect to the region-specific input parameters.

\section{Comparison with Other GMM}

GMM for VCGM interface subduction zone earthquakes for NEI is not yet develop. We have validated our present GMM for VCGM with the available recorded events on Site Class C and also compared with Rahman and Chhangte (2021) GMM for horizontal component of ground motions for NEI interface subduction zone earthquakes. We have also compared our present GMM for VCGM with the Abrahamson et al. (2016) global interface earthquakes.

In this study, we developed GMM for VCGM on hard rock level corresponding to $\mathrm{V}_{\mathrm{S} 30}=2,800$ $\mathrm{m} / \mathrm{s}$ which is scaled to Site Class $\mathrm{C}\left(\mathrm{V}_{\mathrm{S} 30} \approx 400\right.$ to $\left.500 \mathrm{~m} / \mathrm{s}\right)$ using site coefficients calculated by Singh et al. (2016). We also checked our model with Abrahamson et al. (2016) GMM which is a function of $\mathrm{V}_{\mathrm{S} 30}$. During comparison with Abrahamson et al. (2016) model, we have considered average $\mathrm{V}_{\mathrm{S} 30} \approx 560 \mathrm{~m} / \mathrm{s}$ for Site Class $\mathrm{C}$. We have also checked our GMM for VCGM with Rahman and Chhangte (2021) at Site Class C of the horizontal component of ground motions.

We have checked our GMM for VCGM of the NEI interface earthquakes with the strong motion records for $\mathrm{M}_{\mathrm{w}} 5.3$ on 10 September 1986, $\mathrm{M}_{\mathrm{w}} 5.9$ on 18 May 1987, $\mathrm{M}_{\mathrm{w}} 5.8$ on 6 February 1988, $\mathrm{M}_{\mathrm{w}} 6.0$ on 8 May 1997, $\mathrm{M}_{\mathrm{w}} 5.4$ on 9 December 2004, and $\mathrm{M}_{\mathrm{w}} 5.7$ on 3 January 2017 in Figures 5 (a) to (f) respectively. It is seen from Figures 5 (a) to (f) that our GMM for VCGM is not biased with respect to both magnitude and hypocentral distance. We have estimated the residuals, mean residuals \pm standard deviation for Peak Ground Acceleration (PGA) with respect to magnitude which is presented in Figure 6. From Figure 6, it is seen that residuals for PGA are not bias for all range of magnitude. We have also estimated the residuals for VCGM of PGA and Spectral Acceleration $\left(\mathrm{S}_{\mathrm{a}}\right)$ at $2.0 \mathrm{~s}$ with respect to hypocentral distance for the available strong motion records of NEI interface subduction zone earthquakes which are shown in Figures 7 (a) and (b) respectively. It is seen from Figures 6 and 7 (a) to (b) that residuals of PGA and $S_{a}$ with respect to magnitude and hypocentral distance are not bias.

We have compared our GMM for VCGM of the interface earthquakes with the GMM of Rahman and Chhangte (2021) and Abrahamson et al. (2016) for PGA with respect to hypocentral distance for magnitude $\mathrm{M}_{\mathrm{w}} 6.5,7.5,8.5$, and 9.5 which are shown in Figures 8 (a) to (d). We have also 
compared for $S_{\mathrm{a}}$ at $0.25 \mathrm{~s}$ for $\mathrm{M}_{\mathrm{w}} 6.5,7.5,8.5$, and 9.5 with respect to hypocentral distance which are shown in Figures 9 (a) to (d). It is seen from Figures 8 and 9 that our GMM for VCGM give lesser values than Rahman and Chhangte (2021) and Abrahamson et al. (2016).

We also compared our GMM for $S_{a}$ at different time periods with the GMM of Rahman and Chhangte (2021) and Abrahamson et al. (2016) for $\mathrm{M}_{\mathrm{w}}$ 6.5, 7.5, 8.5, and 9.5 at hypocentral distance 50, 100, 150 and $200 \mathrm{~km}$ which are shown in Figures 10 (a) to (d) respectively. It is observed that our GMM gives lower values than our GMM give lesser values than Rahman and Chhangte (2021) and Abrahamson et al. (2016).

It is observed from Figures 8 to 10 that our GMM based on combined models give less PGA and $S_{\mathrm{a}}$ values as compared to Rahman and Chhangte (2021) and Abrahamson et al. (2016) GMM. Our GMM for VCGM give lower values because Rahman and Chhangte (2021) and Abrahmason et al. (2016) calculated GMM for horizontal component of ground motions. It is also observed that these differences may also arises due to different value of $\mathrm{V}_{\mathrm{S} 30}$.

\section{Conclusions}

In this study, we developed a new GMM for VCGM of interface subduction zone earthquakes for NEI based on Boore's point source and FINSIM finite fault model (combined model). Our GMM is based on simulated 50,000 vertical component of ground motions (VCGM) database for magnitude $\mathrm{M}_{\mathrm{w}} 5.0$ to 9.5 and hypocentral distances 30 to $300 \mathrm{~km}$. These VCGM samples are theoretically simulated using the region-specific seismic input parameters related to VCGM in NEI interface earthquakes.

Our present GMM for VCGM is well fitted and un-bias with respect to both magnitude and hypocentral distance. This model will give suitable VCGM parameters for NEI interface subduction earthquakes which will be further useful in estimating the seismic hazard for the region.

\section{Data Availability}

Earthquake database used in this study are obtained from Rahman and Chhangte (2021), Geological Survey of India, International Seismological Centre and National Earthquake Information Centre catalog. The ground motions database from seismic research centre used in this study can be accessed using unique identifier system. 
198 Abrahamson NA, Gregor NJ, and Addo K (2016) BC Hydro ground motion models for subduction 199 equations for subduction earthquakes, Earthq. Spec. 32 23-44.

200 Beresnev IA, and Atkinson GM (1999) Generic finite-fault model for ground motions prediction in 201 eastern North America, Bull. Seism. Soc. Am. 89 608-625.

202 Boore DM (1983) Stochastic of high frequency ground motions based on seismological models of the 203 radiated spectra, Bull. Seism. Soc. Am. 73 1856-1894.

204 Boore DM (2003) Simulation of ground motion using the stochastic method, Pure Appl. Geophys. 160 205 635-676.

206 Cagnan Z, Akkar S, Kale O, and Sandikkaya A (2017) A model for predicting vertical component peak 207 ground acceleration (PGA), peak ground velocity (PGV), and 5\% damped pseudospectral acceleration 208 (PSA) for Europe and the Middle East, Bull. Earthq. Engg. 15 2617-2643.

209 Goswami HC, and Sharma SK (1982) Probabilistic earthquake expectancy in the northeast Indian region, 210 Bull. Seism. Soc. Am. 72 999-1009.

211 Iyengar RN, and Raghukanth STG (2004) Attenuation of strong ground motion in peninsular India, 212 Seism. Res. Lett. 75 530-539.

213 Joyner WB, and Boore DM (1981) Peak horizontal Acceleration and velocity from strong motion records 214 including records from the 1979, Imperial Valley, California earthquakes, Bull. Seism. Soc. Am. 71 20112152038.

216 Oldham RD (1899). Reports of the great earthquake of $12^{\text {th }}$ June, 1987, Mem. Geo. Surv. India. 29 K. 217 Paul, Trench, Trübner \& co.

218 Raghukanth STG (2008) Simulation of strong ground motion during the 1950 great Assam earthquake, 219 Pure Appl. Geophys. 165 1761-1787.

220 Rahman T (2008) Engineering approach to seismic hazard analysis in the north-eastern region of India, 221 Ph.D. Thesis, Department of Civil Engineering, Indian Institute of Science, Bangalore.

222 Rahman T (2012) Seismological model parameters for the northeastern and its surrounding region of 223 India, Earthq. Sci. 25 323-338.

224 Rahman T, and Chhangte RL (2021) A new ground motion model (GMM) for Northeast India (NEI) and 225 its adjacent countries for interface earthquakes considering both strong motion records and simulated 226 data, Pure Appl. Geophys. 178 1021-1045.

227 Singh NM, Rahman T, and Wong IG (2016) A new ground motion prediction model for northeastern 228 India (NEI) crustal earthquakes, Bull. Seism. Soc. Am. 106 1282-1297.

229 Steckler MS, Mondal DR, Akhter SH, Seeber L, Feng L, Gale J, Hill EM, and Howe M (2016) Locked 230 and loading megathrust linked to active subduction beneath the Indo-Burman ranges, Nat. Geo. 9(8) 615. 
231

\begin{tabular}{|} 
Table 1. \\
\hline Date
\end{tabular}

\begin{tabular}{|c|c|c|}
\hline $\begin{array}{c}\text { Date } \\
(\mathrm{yy} / \mathrm{mm} / \mathrm{dd})\end{array}$ & $\begin{array}{c}\text { Magnitude } \\
\left(\mathrm{M}_{\mathrm{w}}\right)\end{array}$ & $\begin{array}{c}\text { Strike } \\
(\text { Degree })\end{array}$ \\
\hline $2018 / 01 / 07$ & 5.6 & 210 \\
\hline $2017 / 01 / 03$ & 5.7 & 147 \\
\hline $2014 / 11 / 20$ & 5.6 & 156 \\
\hline $2013 / 03 / 02$ & 5.2 & 329 \\
\hline $2009 / 09 / 21$ & 6.3 & 27 \\
\hline
\end{tabular}

\begin{tabular}{|l|l|}
\hline $2007 / 11 / 11$ & 5.5 \\
\hline
\end{tabular}

\begin{tabular}{l|l}
$2004 / 12 / 09$ & 5.4 \\
\hline
\end{tabular}

$2003 / 07 / 26$

$1997 / 05 / 08$

$1988 / 02 / 06$

$1987 / 05 / 18$

$1986 / 09 / 10$

\begin{tabular}{l|l|l}
6.3 & 27 & 19 \\
\hline 5.4 & 243 & 22 \\
\hline
\end{tabular}

Iling Parameters for VCGM of NEI interface earthquakes

236

237

238

239

Table 2. Calculated VCGM quality factor $\left(Q_{V}\right)$ values for NEI interface earthquakes

\begin{tabular}{|c|c|c|}
\hline $\begin{array}{c}\text { Date } \\
\text { (yy-mm-dd) }\end{array}$ & $\begin{array}{c}\text { Magnitude } \\
\left(\mathrm{M}_{\mathrm{w}}\right)\end{array}$ & $\begin{array}{c}\text { Vertical Q } \\
\left(Q_{V}\right),\left(\sigma_{I}\right)\end{array}$ \\
\hline $1986-09-10$ & 5.3 & $101.26 f^{0.92},(12.7,0.042)$ \\
\hline $1987-05-18$ & 5.9 & $114.96 f^{0.96},(15.2,0.023)$ \\
\hline $1988-02-06$ & 5.8 & $108.57 f^{0.98},(14.6,0.032)$ \\
\hline $1997-05-08$ & 6.0 & $111.29 f^{0.94},(13.6,0.029)$ \\
\hline $2003-07-26$ & 5.7 & $104.33 f^{0.95},(15.3,0.058)$ \\
\hline $2004-12-09$ & 5.4 & $105.91 f^{0.93},(13.4,0.022)$ \\
\hline $2007-11-11$ & 5.5 & $102.87 f^{0.97},(12.9,0.025)$ \\
\hline $2009-09-21$ & 6.3 & $121.38 f^{0.99},(13.8,0.04)$ \\
\hline $2013-03-02$ & 5.2 & $115.56 f^{0.93},(14.2,0.03)$ \\
\hline $2014-11-20$ & 5.6 & $90.78 f^{0.94},(16.4,0.05)$ \\
\hline $2017-01-03$ & 5.7 & $89.27 f^{0.95},(15.8,0.045)$ \\
\hline $2018-01-07$ & 5.6 & $100.16 f^{0.96},(12.4,0.05)$ \\
\hline
\end{tabular}

Table 3. Ranges for VCGM of GMM input parameters

\begin{tabular}{|c|c|c|}
\hline Parameters & Distribution & Ranges \\
\hline Cut off frequency & Uniform & $20-50 \mathrm{~Hz}$ \\
\hline Radiation coefficient & Uniform & $0.48-0.64$ \\
\hline Focal depth & Uniform & $10-50 \mathrm{~km}$ \\
\hline Stress parameter & Uniform & $110-280 \mathrm{bars}$ \\
\hline & & $\log _{10}\left(Q_{0}\right)=2.34 \pm 0.16$ \\
Attenuation model & Uniform & $\eta=02 \pm 0.007$ \\
& & $\eta=0.91-0.99$ \\
\hline Time duration model & Uniform & $\mathrm{R}(16.5 / 60)$, if $\mathrm{R}<60 \mathrm{~km}$ \\
& & $16.5+0.05(\mathrm{R}-60)$, if $\mathrm{R} \geq 60 \mathrm{~km}$ \\
\hline
\end{tabular}


\begin{tabular}{l|l|l} 
Kappa & - & $0.006 \mathrm{~s}$ \\
\hline
\end{tabular}

241 Table 4. Magnitude and ranges of hypocentral distance for VCGM of NEI interface earthquakes

\begin{tabular}{|c|c|c|c|}
\hline $\begin{array}{c}\text { Moment Magnitude, } \\
\mathrm{M}_{\mathrm{w}}\end{array}$ & $\begin{array}{c}\text { Hypocentral Distance, } \\
\mathrm{R}(\mathrm{km})\end{array}$ & No. of distance samples & No. of samples \\
\hline 4.5 & $30-300$ & 100 & 10000 \\
5.0 & $30-300$ & 100 & 10000 \\
5.5 & $30-300$ & 100 & 10000 \\
6.0 & $30-300$ & 100 & 10000 \\
6.5 & $30-300$ & 100 & 10000 \\
\hline \multicolumn{3}{|c|}{ Total no. of samples } \\
\hline
\end{tabular}

242

243
244

245

246

247

248

249

Table7. Variable regre
\begin{tabular}{|c|c|}
\hline $\mathrm{n}$ & 0.6596 \\
\hline $\mathrm{c}$ & 1.6132 \\
\hline$\theta_{3}$ & 0.063 \\
\hline$\theta_{4}$ & 0.645 \\
\hline$\theta_{5}$ & 0.33 \\
\hline$\theta_{7}$ & 0.218 \\
\hline $\mathrm{C}_{2}$ & 8.72 \\
\hline
\end{tabular}

Table 5. Generic modelling parameters for VCGM of NEI interface earthquakes

\begin{tabular}{|c|c|}
\hline Parameters & Parameter Value \\
\hline Quality factor & $106.84 \mathrm{f}^{0.95}$ \\
\hline Geometric Spreading & $\mathrm{G}=1 / \mathrm{R} \quad$ for $\mathrm{R}<100 \mathrm{~km}$ \\
\cline { 2 - 3 } & $\mathrm{G}=1 /(10 \sqrt{\mathrm{R}}) \quad$ for $\mathrm{R}>100 \mathrm{~km}$ \\
\hline Path Duration Model & $\mathrm{TP}=\mathrm{R} \times(16.5 / 60) \quad[\mathrm{R}<60 \mathrm{~km}]$ \\
& $\mathrm{TP}=16.5+0.05 \times(\mathrm{R}-60) \quad[\mathrm{R} \geq 60 \mathrm{~km}]$ \\
\hline Crustal Amplification & Singh et al. (2016) \\
\hline Kappa & $0.006 \mathrm{~s}$ \\
\hline Stress Parameters & 180 bars \\
\hline Window Functioning & Saragoni-Hart (Beresnev and Atkinson, 1999) \\
\hline Crustal Shear Wave Velocity & 3.6 km/s (Singh et al. (2016) \\
\hline Rupture Velocity & 0.8 X Shear wave velocity \\
& (Beresnev and Atkinson, 1999) \\
\hline Crustal Density & 2.8 gm/cc (Singh et al., 2016) \\
\hline Fault-Slip Distribution & Uniform \\
\hline Stochastic Trial & 3 (Beresnev and Atkinson, 1999) \\
\hline
\end{tabular}

Table 6. Regression relations between rupture dimensions and moment magnitude, the multiple determination coefficient $\left(\mathrm{R}^{2}\right)$ and total numbers of regression points $(\mathrm{N})$ for interface subduction earthquakes (Strasser et al., 2010), where S.E is the standard deviation of coefficient under consideration

\begin{tabular}{|c|c|c|c|c|c|c|c|}
\hline S1 No. & $\mathrm{a}$ & S.E (a) & $\mathrm{b}$ & S.E (b) & $\sigma$ & $\mathrm{R}^{2}$ & $\mathrm{~N}$ \\
\hline 1 & 4.868 & 0.141 & 1.392 & 0.277 & 0.277 & 0.814 & 95 \\
\hline 2 & 4.410 & 0.277 & 1.805 & 0.392 & 0.392 & 0.634 & 85 \\
\hline 3 & 4.441 & 0.179 & 0.846 & 0.286 & 0.286 & 0.805 & 85 \\
\hline
\end{tabular}


251 Table 8. Variable regression coefficients for $\left(\mathrm{S}_{\mathrm{a}} / \mathrm{g}\right)$ at 5\% damping for VCGM

\begin{tabular}{|c|c|c|c|c|c|c|c|c|}
\hline Period & $\mathbf{V}_{\text {lin }}$ & $\mathbf{b}$ & $\boldsymbol{\theta}_{\mathbf{1}}$ & $\boldsymbol{\theta}_{\mathbf{2}}$ & $\boldsymbol{\theta}_{\mathbf{6}}$ & $\boldsymbol{\theta}_{\mathbf{8}}$ & $\boldsymbol{\theta}_{\mathbf{9}}$ & $\boldsymbol{\theta}_{\mathbf{1 0}}$ \\
\hline 0.000 & 625 & -0.789 & 2.120 & -0.846 & -0.0089 & 0.650 & -0.0081 & 0.528 \\
\hline 0.020 & 654 & -0.895 & 2.121 & -0.908 & -0.0089 & 0.580 & -0.0083 & 0.668 \\
\hline 0.050 & 761 & -1.080 & 2.215 & -0.636 & -0.0090 & 0.769 & -0.0086 & 0.732 \\
\hline 0.075 & 784 & -1.284 & 2.316 & -0.465 & -0.0092 & 0.882 & -0.0084 & 0.845 \\
\hline 0.100 & 746 & -1.455 & 2.432 & -0.274 & -0.0093 & 0.962 & -0.0091 & 0.871 \\
\hline 0.150 & 634 & -1.567 & 2.541 & -0.955 & -0.0094 & 1.121 & -0.0096 & 0.837 \\
\hline 0.200 & 541 & -1.657 & 2.643 & -0.136 & -0.0096 & 1.241 & -0.0104 & 0.811 \\
\hline 0.250 & 473 & -1.749 & 2.725 & -0.905 & -0.0097 & 1.281 & -0.0101 & 0.761 \\
\hline 0.300 & 429 & -1.756 & 2.659 & -0.473 & -0.0096 & 1.417 & -0.0113 & 0.690 \\
\hline 0.400 & 368 & -1.710 & 2.543 & -0.712 & -0.0095 & 1.463 & -0.0119 & 0.527 \\
\hline 0.500 & 334 & -1.625 & 2.349 & -0.552 & -0.0094 & 1.448 & -0.0141 & 0.435 \\
\hline 0.600 & 315 & -1.597 & 2.127 & -0.654 & -0.0094 & 1.369 & -0.0156 & 0.382 \\
\hline 0.750 & 304 & -1.302 & 2.093 & -0.028 & -0.0093 & 1.215 & -0.0184 & 0.313 \\
\hline 1.000 & 301 & -0.682 & 1.967 & -0.841 & -0.0091 & 0.896 & -0.0223 & 0.215 \\
\hline 1.500 & 297 & -0.199 & 1.896 & -0.654 & -0.0090 & 0.249 & -0.0372 & 0.202 \\
\hline 2.000 & 294 & -0.104 & 1.734 & -0.165 & -0.0088 & 0.244 & -0.0439 & 0.196 \\
\hline 2.500 & 289 & -0.060 & 1.602 & -0.561 & -0.0088 & -0.435 & -0.0481 & 0.194 \\
\hline 3.000 & 289 & -0.013 & 1.496 & -0.223 & -0.0087 & -0.406 & -0.0563 & 0.193 \\
\hline 4.000 & 287 & 0.000 & 1.352 & -0.615 & 0.0085 & -0.378 & -0.0591 & 0.192 \\
\hline 5.000 & 286 & 0.000 & 1.157 & -0.021 & 0.0083 & 0.362 & -0.0597 & 0.189 \\
\hline
\end{tabular}

252

253

254

255

Table 9. Estimated standard deviation of GMM for VCGM parameters in sensitivity analysis

\begin{tabular}{|c|c|c|}
\hline Serial no. & Model uncertainty parameters & Standard deviation (ln) \\
\hline 1 & Focal depth & \pm 0.083 \\
\hline 2 & Cut-off frequency & \pm 0.072 \\
\hline 3 & Stress drop & \pm 0.096 \\
\hline 4 & Radiation pattern & \pm 0.042 \\
\hline 5 & Anelastic attenuation & \pm 0.136 \\
\hline 6 & Geometric attenuation & \pm 0.124 \\
\hline 7 & Time duration & \pm 0.086 \\
\hline 8 & $\kappa$ (kappa) & \pm 0.363 \\
\hline 9 & Site coefficient & \pm 0.416 \\
\hline 10 & Total uncertainties & \pm 0.587 \\
\hline
\end{tabular}




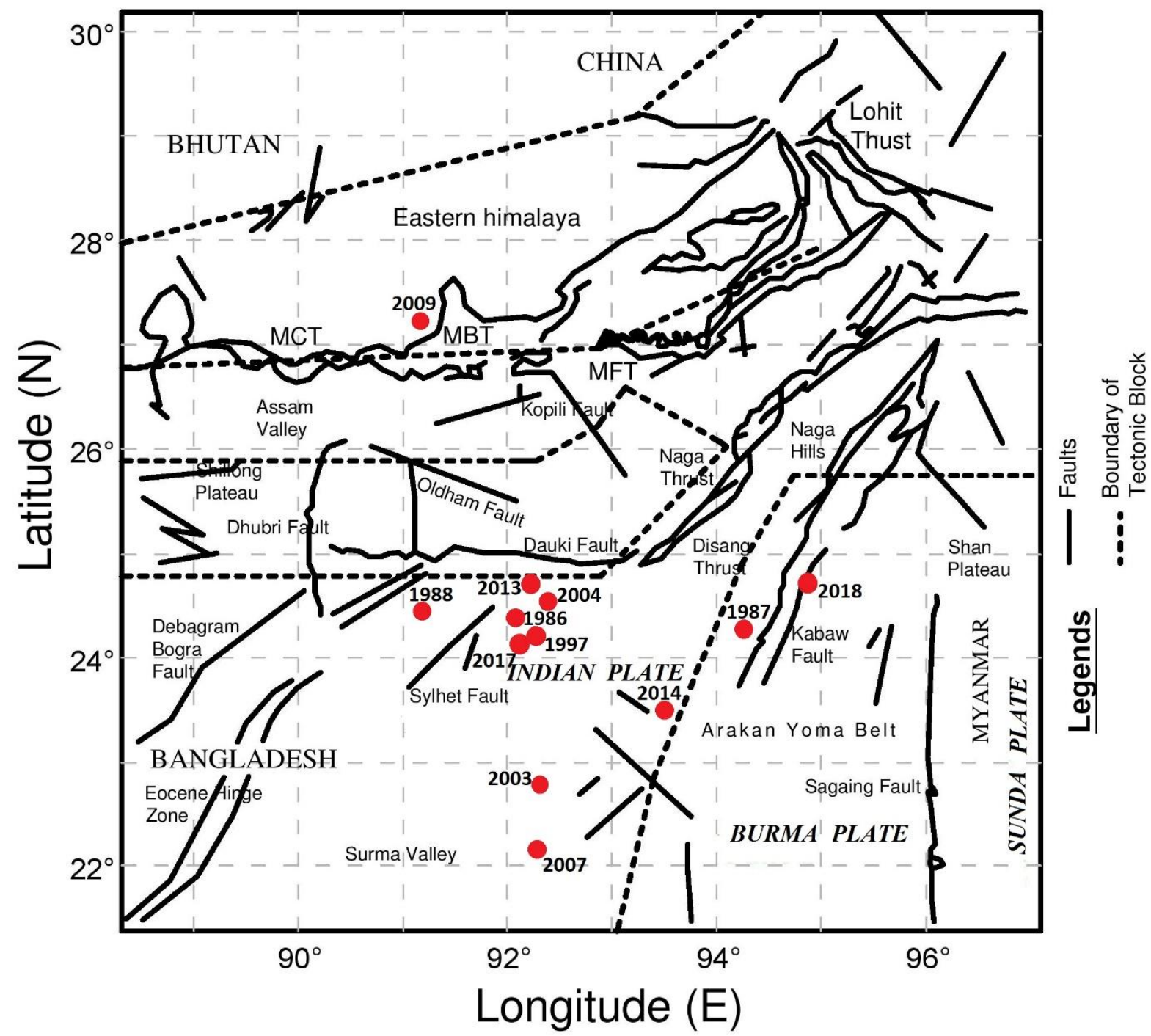

Figure 1. Seismotectonic map of NEI. Coordinates of earthquake epicentres considered in this 258 article are shown in the figure. 

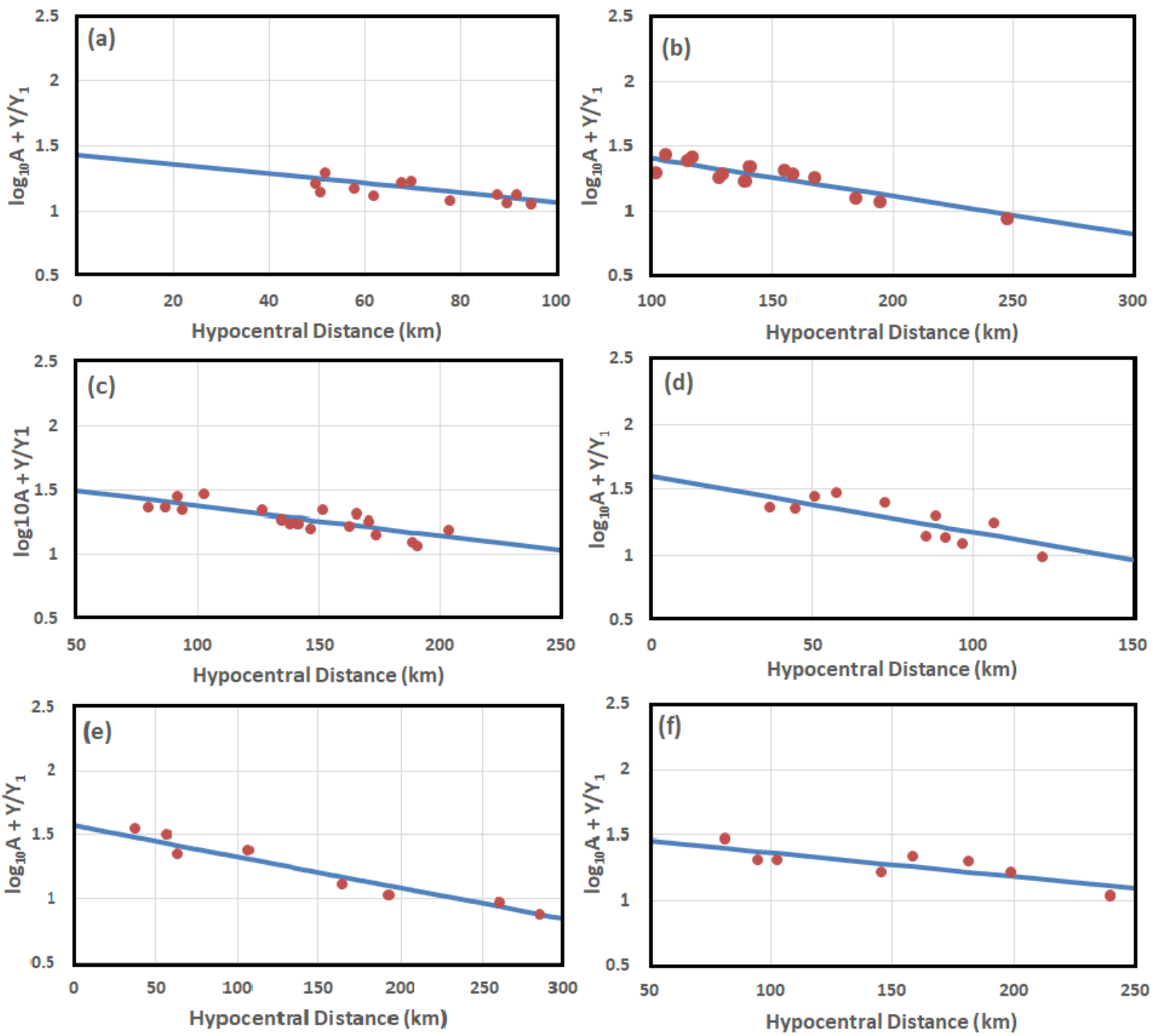

Figure 2. Variation of $\log _{10} \mathrm{~A}+\mathrm{Y} / \mathrm{Y}_{1}$ versus $\mathrm{R}(\mathrm{km})$ for $\mathrm{VCGM}$ at $0.2 \mathrm{~Hz}$ for (a) 10 September 1986, (b) 18 May 1987, (c) 6 February 1988, (d) 8 May 1997, (e) 9 December 2004 and (f) 3 January 2017. Y = $\log _{10} \mathrm{R}(\mathrm{R}<100 \mathrm{~km})$ and $\mathrm{Y}_{1}=5 \log _{10} \mathrm{R}(\mathrm{R}>100 \mathrm{~km})$. 

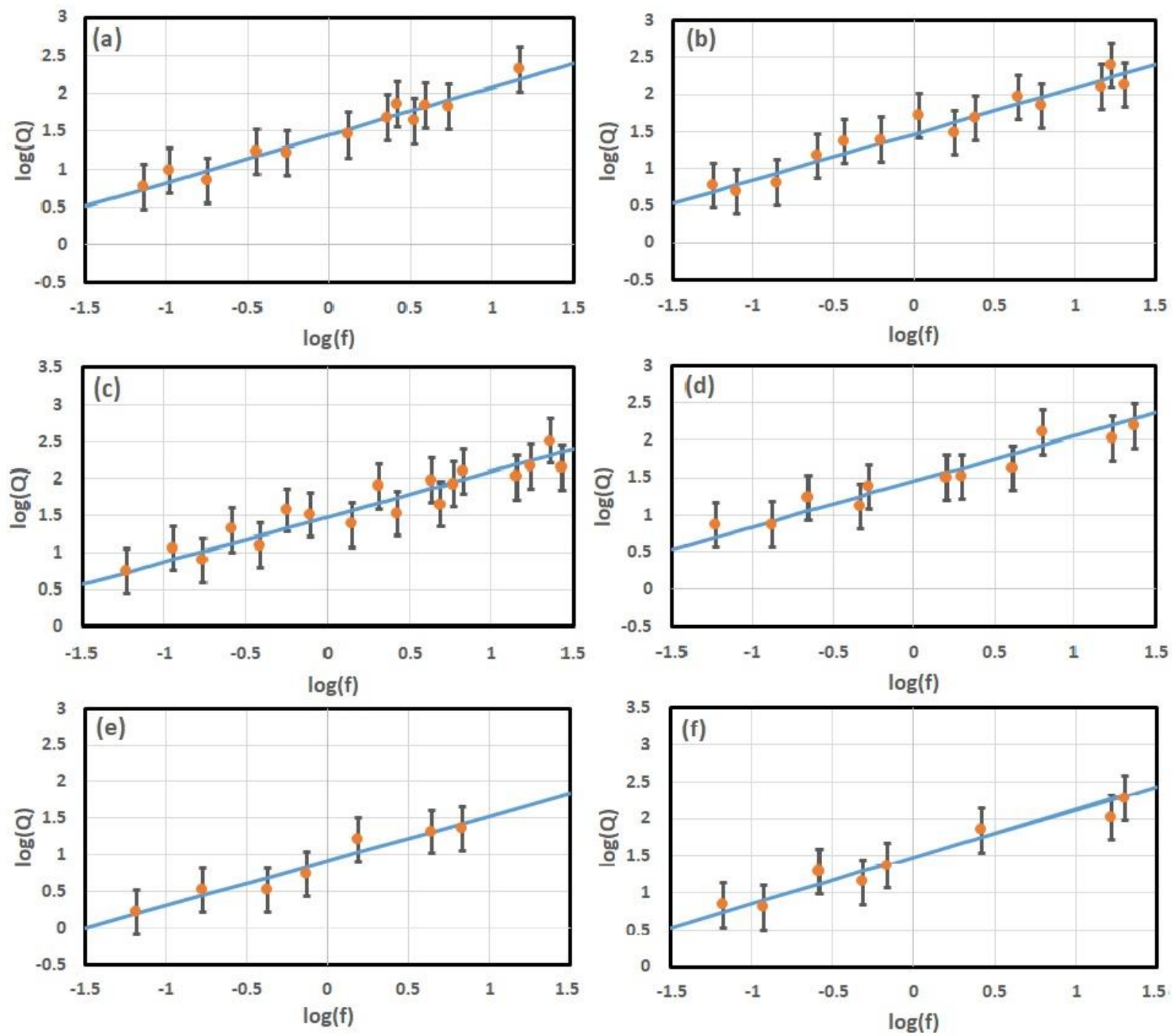

Figure 3. Weighted average of the $\log _{10} \mathrm{Q}$ versus $\log _{10}$ for VCGM of (a) 10 September 1986, (b) 18 May 1987, (c) 6 February 1988, (d) 8 May 1997, (e) 9 December 2004 and (f) 3 January 2017 earthquakes.
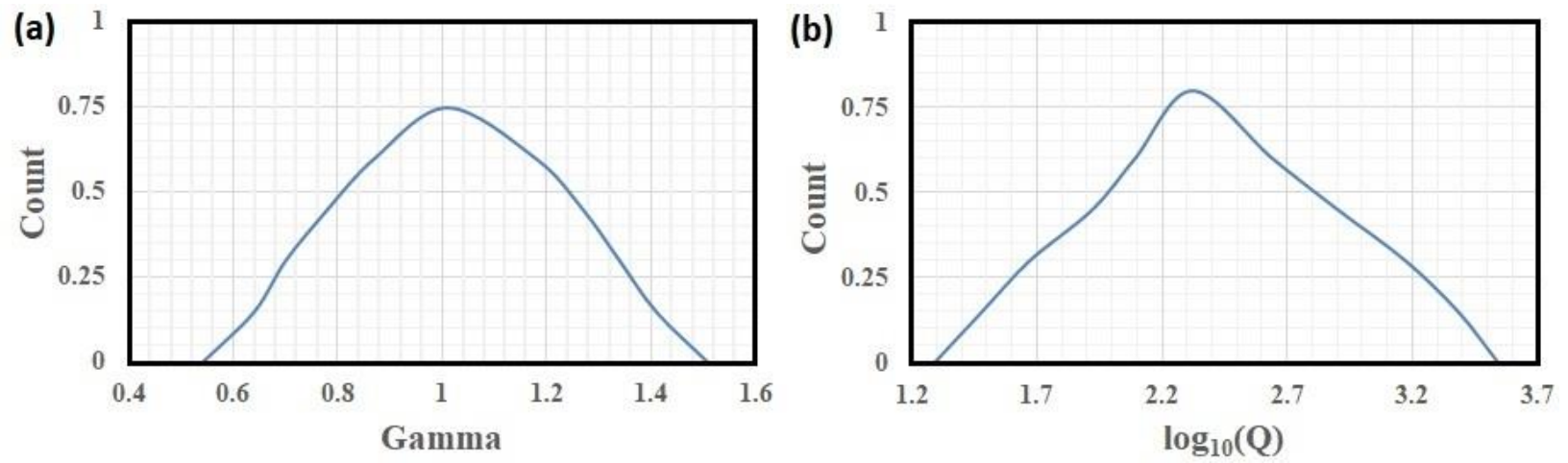

Figure 4. Distribution for the attenuation parameters for VCGM of NEI interface earthquakes after 

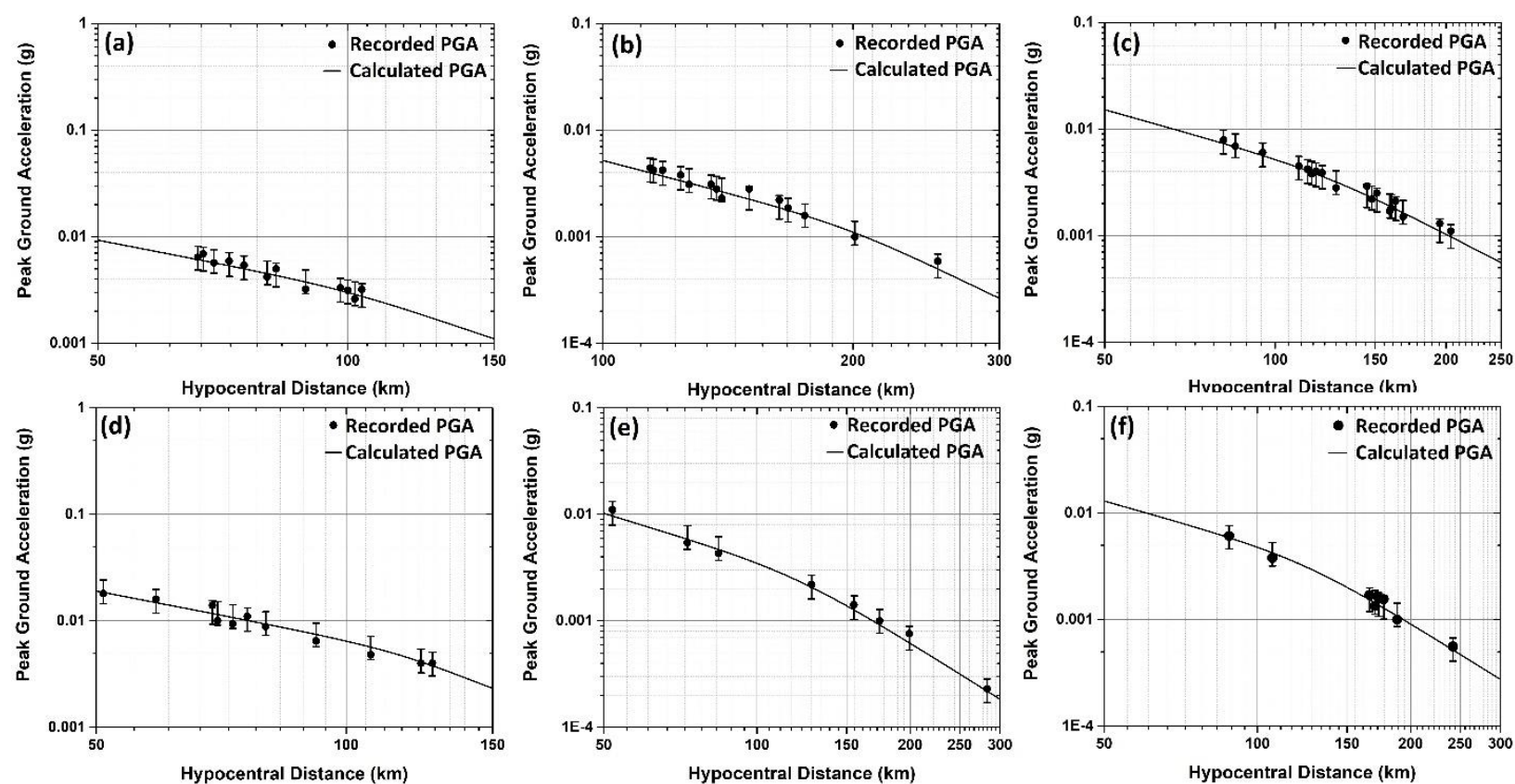

Figure 5. Predicted and recorded PGA values for VCGM at Site Class C for (a) 10 September 1986, (b) 18 May 1987, (c) 6 February 1988, (d) 8 May 1997, (e) 9 December 2004 and (f) 3 January 2017 earthquakes. Error/vertical bar represent the standard deviations for VCGM of GMM.

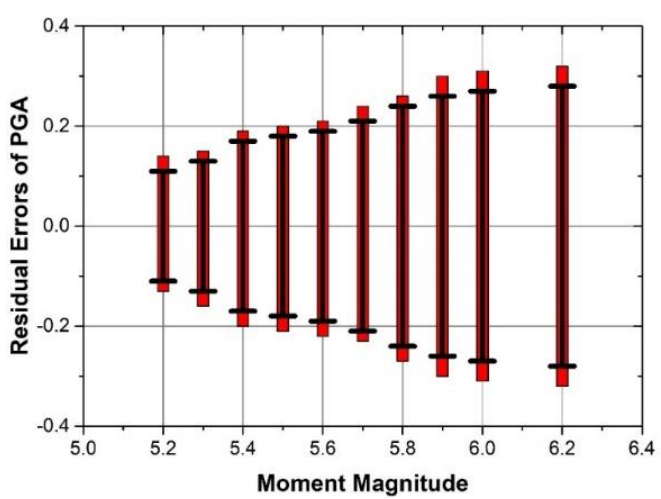

Figure 6. Distribution of PGA residuals for VCGM with respect to $M_{w}$. The residuals for each earthquake events are shown with black vertical line with three horizontal bars which indicate the ranges of average \pm standard deviations of residuals.
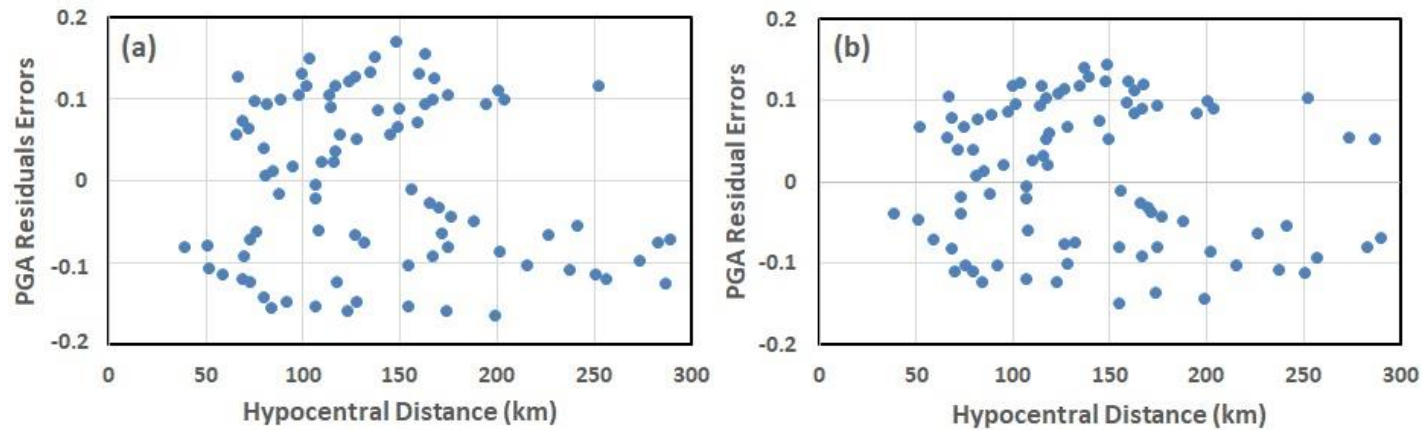

Figure 7. Distribution of the residuals for VCGM of (a) PGA, (b) $2.0 \mathrm{~s} \mathrm{~S}_{\mathrm{a}}$ with respect to hypocentral distance $(\mathrm{km})$. 

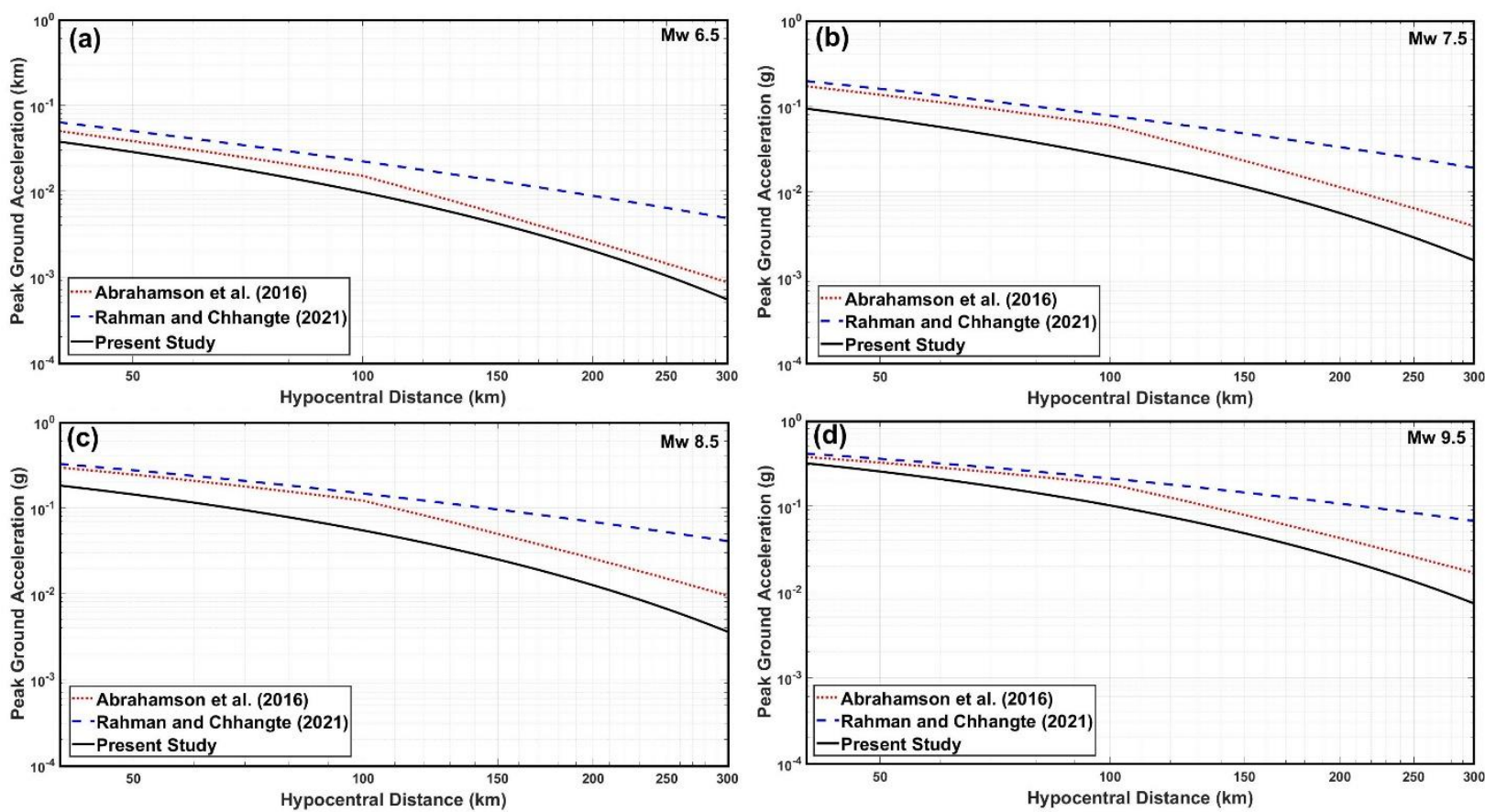

Figure 8. Comparison of Peak Ground Acceleration for VCGM of present GMM with Rahman and Chhangte (2021) and Abrahamson et al. (2016) for $\mathrm{M}_{\mathrm{w}}$ (a) 6.5, (b) 7.5, (c) 8.5, and (d) 9.5 w.r.t. hypocentral distance $(\mathrm{km})$ respectively.
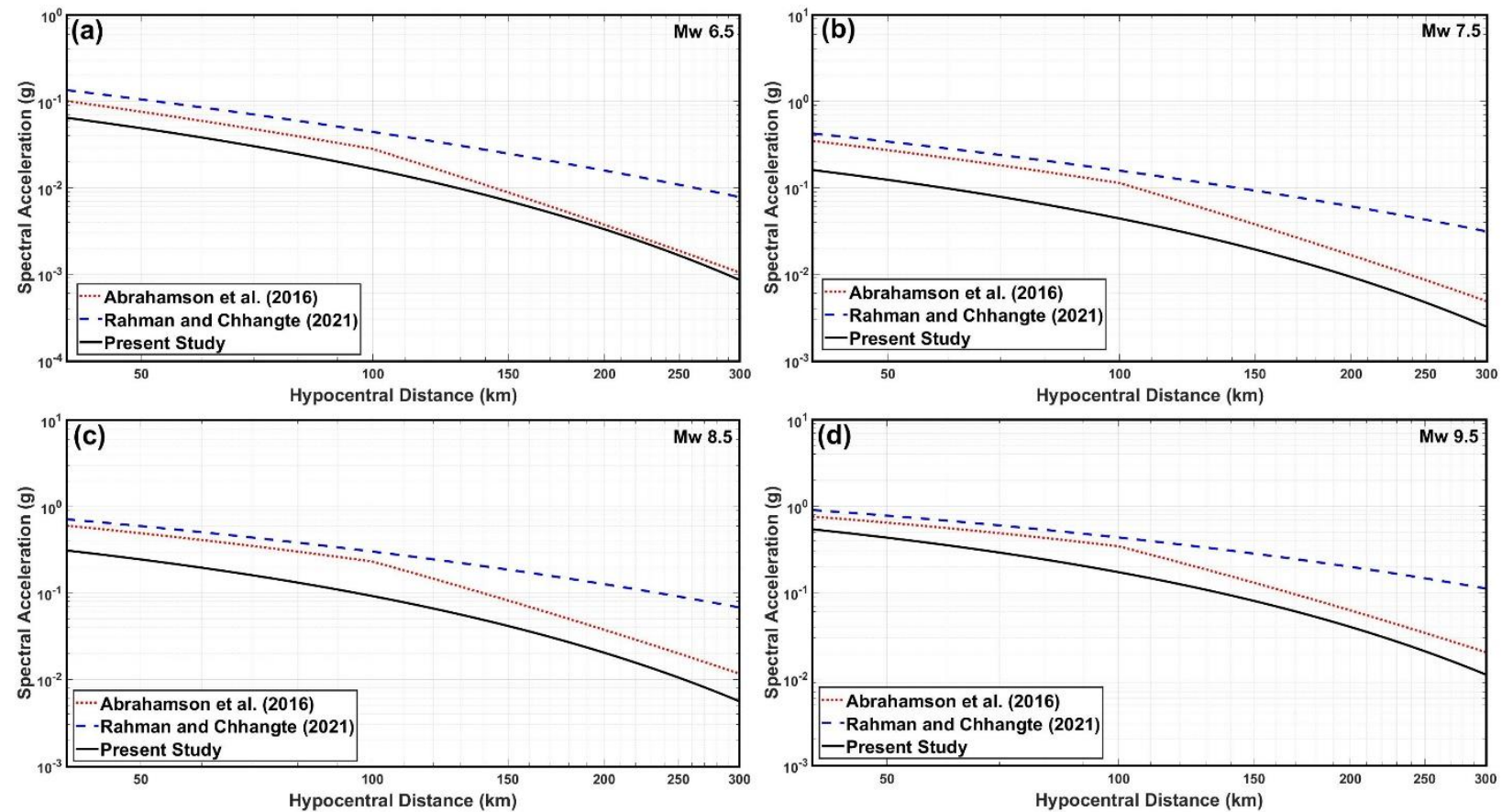

Figure 9. Comparison of Spectral Acceleration for VCGM of present GMM with Rahman and Chhangte (2021) and Abrahamson et al. (2016) for $\mathrm{M}_{\mathrm{w}}$ (a) 6.5, (b) 7.5, (c) 8.5, and (d) 9.5 at 0.25 s w.r.t. hypocentral distance $(\mathrm{km})$ respectively. 

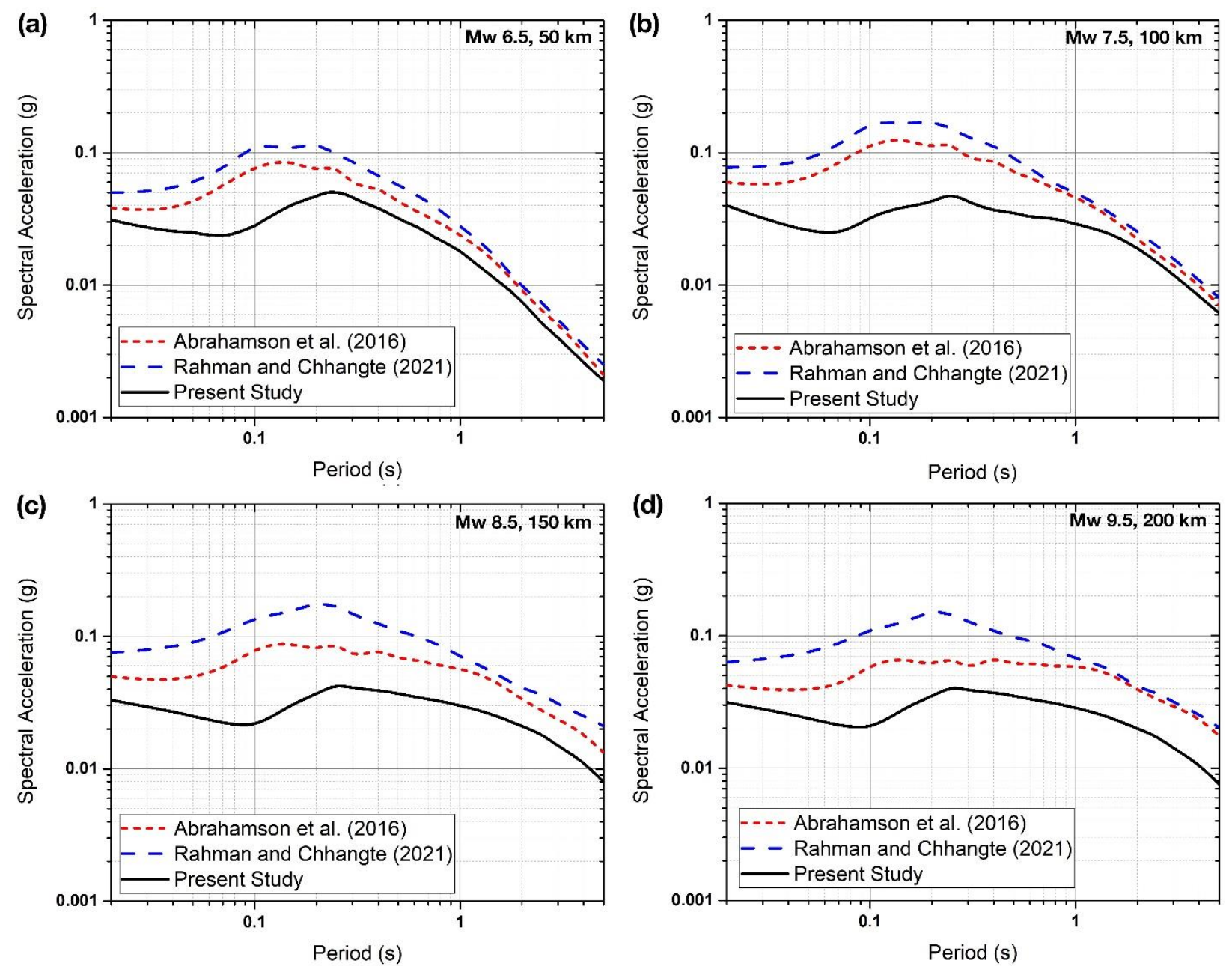

Figure 10. Comparison of Spectral Acceleration for VCGM of present GMM with Rahman and Chhangte (2021) and Abrahamson et al (2016) for $\mathrm{M}_{\mathrm{w}}$ (a) 6.5, (b) 7.5, (c) 8.5, and (d) 9.5 at a hypocentral distance of 50, 100, 150 and $200 \mathrm{~km}$ w.r.t time periods ( 0.01 to $5.0 \mathrm{~s}$ ) respectively. 